\title{
Screening of Antimicrobial Residues among Table Eggs Using Disc Diffusion Assay at Erbil Governorate, Kurdistan Region, Iraq
}

\author{
Dhary Alewy ALMASHHADANY ${ }^{1 *}$ \\ ${ }^{1}$ Department of Medical Lab Science (DMLS), College of Science (CSCN), Knowledge University (KNU), Irak \\ *corresponding author: dhary.hammed@knu.edu.iq
}

Bulletin UASVM Animal Science and Biotechnologies 77(2)/2020

ISSN-L 1843-5262; Print ISSN 1843-5262; Electronic ISSN 1843-536X

DOI:10.15835/buasvmcn-asb: 2020.0015

\begin{abstract}
The existence of antimicrobial residues in food of animal origin is a safety concern worldwide. This study investigated the occurrence of such residues in table eggs collected from Erbil city (Iraq) markets according to shell color, location, and season. Results showed that the total proportion was $15.2 \%$. The differences were not significant for the shell color (White color 13.7\%; Brown color 16.8\%), location (Urban 16.4\%; Rural 13.8\%), and months (July 12.1\%, August 13.5\%, September 18.8\%, October 15.7\%, December 16.9\%, and November $14.1 \%)$. Such level of residue contamination requires a response from in-charge Iraqi health authorities to regulate antibiotics usage and ensure food safety.
\end{abstract}

Keywords: antimicrobial residues, table eggs, disc diffusion assay.

\section{Introduction}

Eggs constitute an extremely important component of healthy foods for humans owing to the contents of essential amino acids with a biological value that reaches $93.7 \%$. Around $12.6 \%$ of the edible part of an egg is protein. The internal edible core has two compartments; the yolk (31\%) and the albumen (59\%). The yolk contains the majority of essential nutrients particularly fat-soluble vitamins, (A, D, E, and $\mathrm{K})$, and minerals necessary for body systems to function effectively (Ketta \& Tůmová, 2016; Réhault-Godbert et al., 2019). Folic acid in eggs may help in the prevention of congenital disabilities, such as spina bifida and macular degeneration, the leading cause of age-related blindness. The accumulation of lutein in the fovea of the retina supports eye health by acting as an antioxidant and by absorbing the damaging blue light (short wavelengths) (Layman \& Rodriguez, 2009; Réhault-Godbert et al., 2019). As other foodstuffs of animal origin, table eggs may become contaminated with antimicrobial residues (ARs). Antimicrobials are widely used in poultry farms as therapeutic agents for infectious diseases and as growth promoters to increase feed efficiency.

After the administration of antimicrobial agents to birds, a small amount of drugs remains in tissues and eggs, as residues known as antimicrobial residues (ARs) (Aidara-Kane et al., 2018; Stella et al., 2020). These drugs are absorbed in the intestine, carried through blood/plasma to the ovary, and deposited in the magnum of the oviduct. Accumulation of ARs in the ampulla, uterus, and the oviducts leads finally to be included in egg albumen during the plumping of the eggs (Donoghue \& Myers, 2000). Despite widespread believe that brown eggs are better than white eggs, scientific evidence suggests negligible nutritional variations between them. The cause of brown color in shells is the pigment protoporphyrin IX deposited 
in the shell during development (Ketta \& Tůmová, 2016). Drugs that are quickly eliminated from the body of the laying hen are also excreted rapidly from the egg component few days after withdrawal or treatment termination. Moreover, the biological half-life of the used drug is essential for drug residue clearance from egg components (Donoghue \& Myers, 2000; Goetting et al., 2011; Rana et al., 2019).

ARs have negative impacts on human health, including adverse effects on the nervous system, reproductive system, and immune system. Disturbance of normal gut microbiota, congenital anomalies, carcinogenic effects, and the emergence of antibiotic-resistant bacteria are also linked to ARs persistence in food (Al-Mashhadany, 2019; Maharjan et al., 2020). The presence of ARs in table eggs above certain limits is considered globally illegal (Sachi et al., 2019). The underlying reason behind such contamination is the farmers' failure to comply with withdrawal periods instructions. Massive and irrational uses of antibiotics are also contributing to general malpractice that also increases ARs in food (Beyene, 2016; Polveiro et al., 2020). A worth mentioning point is that specialized authorities of food safety have set maximum residue limits for authorized antimicrobial agents, while other drugs such as chloramphenicol and metronidazole are unauthorized to be present in food thus, lack maximum residue limits. Additionally, certain antimicrobials such as kanamycin, florfenicol, dicloxacillin, and cloxacillin are not used in animals from which milk or eggs are produced for human consumption (ECR, 2010).

The existence of ARs in poultry meat and table eggs is higher in developing countries compared to developed ones. This might be related to limited inspection authorities and a lack of regular screening tests of ARs (Almashhadany, 2009; Sachi et al., 2019; Cornejo et al., 2020). There was inadequate data on the frequency of ARs occurrence in table eggs at the Erbil governorate (Kurdistan region, Iraq). Hence, this work was carried out to assess the frequency of ARs in table eggs and the relationship between months and ARs occurrence rate.

\section{Materials and methods}

\section{Study design and sampling}

During the period from July 1st to December 31st, 2018, a total of 520 table eggs samples (270 eggs with white shell and 250 eggs with brown shell) were randomly collected from retail food shops in different markets in the Erbil governorate. The samples were placed in a clean container and transported to the Department of Medical Lab Science (DMLS), College of Sciences (CSCN), and Knowledge University (KNU). In the laboratory, samples were either immediately processed or refrigerated at $4{ }^{\circ} \mathrm{C}$ until processing the next day (Ehsani \& Hashemi, 2015).

\section{Detection of ARs in table eggs \\ Preparation of the spore suspension}

Spores suspension of Bacillus subtilis (a reference strain obtained from The Central Veterinary Laboratory, Erbil) was prepared at desired concentration according to a standard method (AlMashhadany et al., 2018). Briefly, thick inoculums of Bacillus subtilis were introduced to the surface of an agar plate (Nutrient agar, HiMedia, India) and incubated at $30^{\circ} \mathrm{C}$ for 10 days to induce sporulation. After the incubation period, colonies were harvested into $10 \mathrm{ml}$ of sterile normal saline and heated at $70^{\circ} \mathrm{C}$ for 10 minutes to kill the vegetative cells. Repeated cycles of washing and centrifugation were performed to obtain a pure endospore suspension.

\section{Disc Diffusion Assay}

Muller-Hinton agar was prepared with a $\mathrm{pH}$ value of $7.3 \pm 0.1$ as recommended by the manufacturing company (HiMedia, India). After cooling to approximately $45^{\circ} \mathrm{C}$, an inoculum of $0.1 \mathrm{ml}$ of endospore suspension was mixed with $100 \mathrm{ml}$ of the agar before solidification. The mixture was poured into Petri dishes and allowed to solidify at room temperature. Plates were used on the same day of preparation or held at the refrigerator and used within one week.

The egg surface was thoroughly cleansed using sterile cotton wool soaked in $70 \%$ alcohol then washed by sterile distilled water. Sterile forceps were used to puncture the egg at the tip to create a small opening from where the albumen was carefully drained out leaving behind the yolk which was transferred into a sterile beaker and then thoroughly homogenized with the albumen. Sterile filter paper disc of $0.6 \mathrm{~cm}$ in diameter was dipped into the homogenized egg yolk and placed gently on the Muller Hinton agar plate previously inoculated with the test organism. The plates were then inverted and incubated aerobically at $37{ }^{\circ} \mathrm{C}$ for 24 hours. 
After the incubation period, plates were examined for the presence or absence of inhibition zones of the test organism around test and control discs. The presence of antibiotic residues in the sample was indicated by the presence of an inhibition zone of the growth of $B$. subtilis around the discs containing samples. The absence of antibiotic residues was indicated by the absence of the inhibition zone around the discs (Almashhadany, 2009; ElNasri et al., 2013). Eggs are one of the most frequently consumed products of animal origin worldwide, therefore, eggs' safety is a substantiated health issue. However, ARs in eggs is an alarming threat that requires screening and mitigation for the public safety of consumers (Guter \& Low, 1971; Krišová \& Kožárová, 2018). This study aimed at screening the frequency of ARs contamination of table eggs in the Erbil city (Iraq).

\section{Statistical analysis}

Data were analyzed using the SPSS software version 25. Confidence intervals of prevalence were estimated by the "exact" Clopper-Pearson method at an alpha level of 0.05. A Chi-square test was used to test the difference between groups.

\section{Results and Discussion}

Results revealed that the occurrence of ARs in 520 table egg samples was 79 (15.2\%) (Table 1). The proportion of positive samples with ARs was $16.8 \%$ in the Brown shell eggs whereas the corresponding proportion was $13.7 \%$ in White shell eggs with no significant difference $\left(\chi^{2}=\right.$ $0.966, P=0.32$ ).

These findings are compatible with previous studies that evaluated ARs in commercial eggs in Egypt (Shehata et al., 2014) and Iran (Ehsani \& Hashemi, 2015).

It should be noted that these results are to be considered cautiously for few reasons. First, certain antibiotics, such as tetracycline $(200 \mu \mathrm{g} / \mathrm{kg}$

Table 1. The proportion of ARs among table eggs samples

\begin{tabular}{lcccc}
\hline \multicolumn{1}{c}{ Egg type } & No. examined & $\begin{array}{c}\text { Positive samples } \\
\text { N (\%) }\end{array}$ & $\mathbf{9 5 \% ~ C I ~}$ & P-value \\
\hline White shell & 270 & $37(13.7)$ & $9.84-18.39$ & 0.32 \\
Brown shell & 250 & $42(16.8)$ & $12.83-22.02$ & \\
\hline Total & 520 & $79(15.2)$ & $12.22-18.57$ & \\
\hline
\end{tabular}

in fish), have high maximum residue limit (MRL) in comparison to other drugs such as ampicillin (50 $\mu \mathrm{g} / \mathrm{kg}$ ) (Aidara-Kane et al., 2018). As a result, such drugs with higher MRL may show positive results in disk diffusion assay (inhibition zones) while their level still in the permissible range. Additionally, qualitative screening methods are usually probe to produce false positive results.

However, a wide range of higher rates was reported from different Asian and African countries using different screening methods (Al-Wabel, 2011; Olatoye \& Kayode, 2012; ElNasri et al., 2013; Hakimzadegan et al., 2014; Islam et al., 2016; Hind et al., 2018). These variations are mostly owing to various factors such as different extents of adherence to withdrawal periods regulations, the diversity of antimicrobials used and different screening methods with different detection limits. Indeed, numerous studies have addressed the violations of withdrawal periods and reported higher rates of ARs in eggs and other animalderived foodstuffs where farmers were less aware of ARs problem (Idowu et al., 2010; Kehinde et al., 2012; Galadima et al., 2018). The violations in ARs occurrence rates were mostly due to a lack of knowledge regarding ARs persistence in foods of animal origin (Galadima et al., 2018). Additionally, the sampled part of the egg may also affect test results. Indeed, different factors affect the distribution of drugs between egg yolk and egg white. These factors are; (i) Lipid solubility as fat-soluble compounds generally occur in yolk, (ii) $p$ Ka value as ionized molecules will distribute in a certain way between phases with different $\mathrm{pH}$ values such as yolk and white, and (iii) protein binding properties of drugs to egg white proteins (Kolanović et al., 2019; Kan \& Petz, 2000).

Regarding to the occurrence of ARs among examined samples, results indicated that the total occurrence rates of ARs in eggs from hens reared in urban and rural areas were $16.4 \%$ and $13.8 \%$, respectively (Table 2 ) and the difference was not 
significant $(P=0.41)$. Also, the result showed the association between the color of shell and location was not significant $(P=0.61)$. Locationbased variations were also reported even within the same country (Donkor et al., 2011; Olatoye \& Kayode, 2012; Yang et al., 2016). Such reports are in good agreement with the findings of the present work. The slight increase in contamination rate in table eggs from urban areas is may attributed to the ease of access to different antibiotics in urban areas in comparison to rural counterparts.

The change in the occurrence rate of ARs was observed through the study period. The highest frequency of ARs was detected in September (18.8\%), while the lowest rate was found in July (12.1\%) (Figure1). Regarding the seasonality of
ARs in eggs, no association was found between winter-spring months and an increase in the occurrence of ARs in eggs $(P=0.14)$. These findings are in good agreement with previously published studies reporting the absence of association of ARs prevalence with seasons (Moscoso et al., 2015; Yang et al., 2016). However, other reports observed a significant increase of ARs in poultry products (meat and eggs) in the wet season (Naeem et al., 2011; Asad, 2012). Conversely, contradictory results were reported from Saudi Arabia where highest ARs rates were found during the dry winter season (Al-Wabel, 2011).

Certain countermeasures can be followed to reduce ARs contamination of poultry products. Raising awareness among farmers and regulated

Table 2. The proportion of ARs in eggs of hens reared in urban and suburban locations

\begin{tabular}{lccccc}
\hline \multirow{2}{*}{ Egg type } & \multicolumn{2}{c}{ Urban } & \multicolumn{2}{c}{ Rural } \\
\cline { 2 - 5 } & No of tested & $\begin{array}{c}\text { Positive samples } \\
(\%)\end{array}$ & No of tested & $\begin{array}{c}\text { Positive samples } \\
(\%)\end{array}$ & P-value \\
\hline White shell & 145 & $21(14.5)$ & 125 & $16(12.8)$ & 0.61 \\
\hline Brown shell & 135 & $25(18.5)$ & 115 & $17(14.8)$ & \\
\hline Total & 280 & $46(16.4)$ & 240 & $33(13.8)$ & 0.41 \\
\hline
\end{tabular}

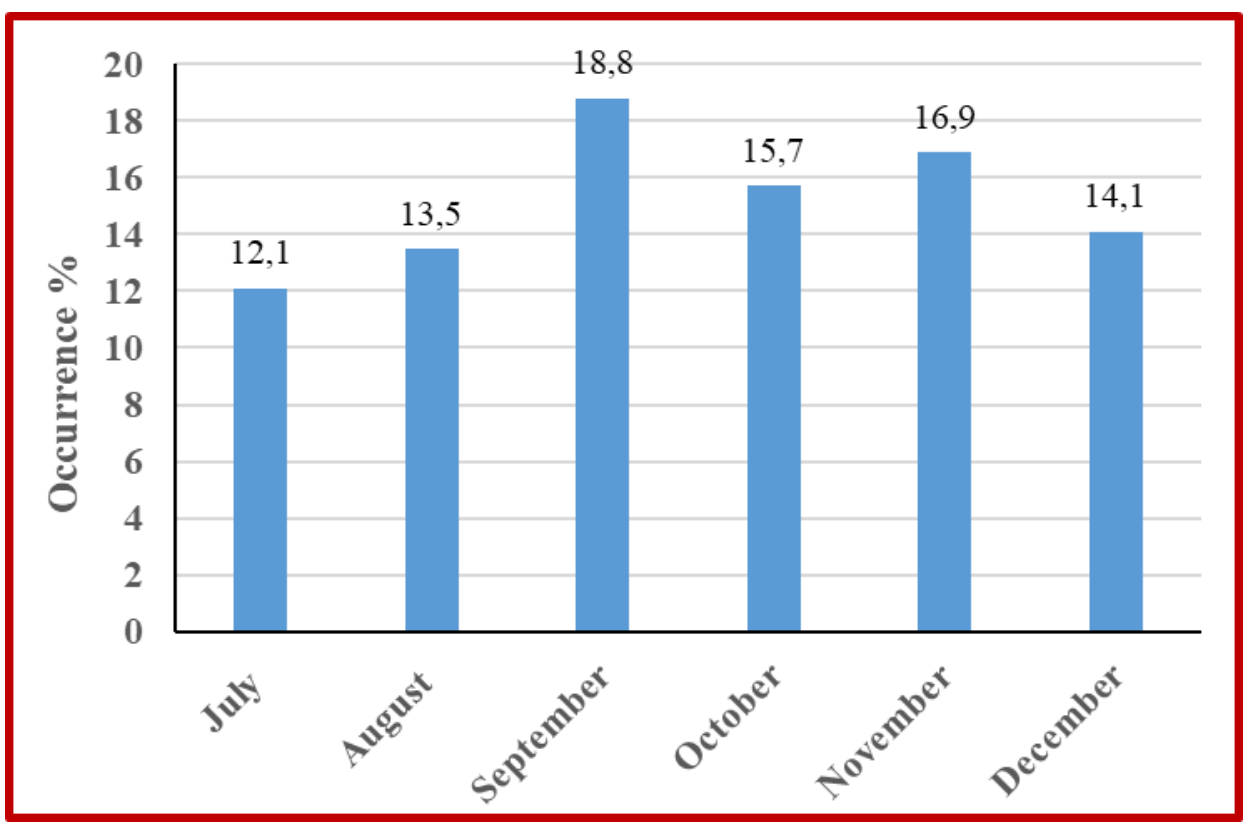

Figure 1. The proportion of ARs in table eggs according to month 
usage of antimicrobial drugs are the most effective strategies. Moreover, regular screening of poultry products especially during the rainy season by simple and in-field tests will undoubtedly aid public health authorities to observe and mitigate the problem of introducing low-quality contaminated products into consumers (Bacanli \& Başaran, 2019; Almashhadany, 2020).

\section{Conclusions}

The existence of antibiotic residue in table eggs is one of the significant public health concerns globally. The occurrence rate of ARs in table egg samples collected from the Erbil governorate is slightly high. There is a need for strict regulation of veterinary drugs in order to guarantee food safety and effective use of such drugs. No association was observed between season and ARs occurrence in eggs. It is crucial to promote awareness among farmers and society regarding the hazards of ARs in food. Further studies addressing the effect of heat treatment particularly chilling and frying on the stability of antiimicrobial residues in table eggs are recommended.

Acknowledgements. Knowledge University is acknowledged for support of the study.

\section{References}

1. Aidara-Kane A, Angulo FJ, Conly J, Minato Y, Silbergeld EK, McEwen SA, \& Collignon PL (2018). World Health Organization (WHO) guidelines on use of medically important antimicrobials in food-producing animals. Antimicrobial Resistance and Infection Control, 7.

2. Almashhadany DA (2009). Detection of antibiotic residues in red meat and the effect of heat treatment on them. Thamar University Journal for Studies and Research, 10: 17-28.

3. Al-Mashhadany DA (2019). Detection of antibiotic residues among raw beef in Erbil city (Iraq) and impact of temperature on antibiotic remains. Italian Journal of Food Safety, 8: 6-10.

4. Almashhadany DA (2020). Monitoring of antibiotic residues among sheep meats at Erbil city and thermal processing effect on their remnants. Iraqi Journal of Veterinary Sciences, 1-6.

5. Al-mashhadany DA, Nahla AA, Zaki AM, \& Mohammad VS (2018). Detection of Antibiotic Residues among Poultry Meat in Erbil City and Impact of Thermal Processing on Remnants. Research Journal of Life Sciences, Bioinformatics, Pharmaceutical and Chemical Sciences, 3: 237-247.
6. Al-Wabel NA (2011). Monitoring of tetracycline residues in table eggs collected from Qassim region, KSA. Journal of Agricultural and Veterinary Sciences, 4: 109-123.

7. Asad F (2012). Antibiotic residue in poultry products. $P h D$ Thesis, University of Agriculture, Faisalabad, Pakistan.

8. Bacanli M \& Başaran N (2019). Importance of antibiotic residues in animal food. Food and Chemical Toxicology, 125: 462-466.

9. Beyene $\mathrm{T}$ (2016). Veterinary drug residues in food-animal products: its risk factors and potential effects on public health. Journal of Veterinary Science \& Technology, 7: 1-7.

10. Donkor ES, Newman M J, Tay S C, Dayie NT, Bannerman \& Olu-Taiwo M (2011). Investigation into the risk of exposure to antibiotic residues contaminating meat and egg in Ghana. Food Control, 22: 869-873.

11. Donoghue DJ, Myers K (2000). Imaging Residue Transfer into Egg Yolks. Journal of Agricultural and Food Chemistry, 48: 6428-6430.

12. ECR (European Commission Regulation) (2010). Commission regulation (EU) No. 37/2010 on pharmacologically active substances and their classification regarding maximum residue limits in foodstuffs of animal origin. Official Journal of the European Commission, 15: 1-75.

13. Ehsani A, Hashemi M (2015). Determination of Antibacterial Drug Residues in Commercial Eggs Distributed in Urmia, Iran. Journal of Food Quality and Hazards Control, 2: 61-65.

14. ElNasri HA, Salman AM, Osman IAM (2013). Detection of antibiotic residues in table eggs using disc assay and premi test in Khartoum state, Sudan. Journal of Veterinary Medicine and Animal Production, 3.

15. Galadima H B, Geidam YA, Shamaki BU, Abdulrahman HI, Ibrahim B, Gulani IA (2018). Screening of Antimicrobial Residue in Commercial Eggs in Maiduguri Metropolis, Borno State. Annual Research \& Review in Biology, 25: $1-6$.

16. Goetting V, Lee KA, Tell LA (2011). Pharmacokinetics of veterinary drugs in laying hens and residues in eggs: a review of the literature. Journal of Veterinary Pharmacology and Therapeutics, 34: 521-556.

17. Guter MM, Low EM (1971). The British Egg Marketing Board 1957-71-A Reassessment. Journal of Agricultural Economics, 22: 247-265.

18. Hakimzadegan M, Khosroshahi KM, Nasab SH (2014). Monitoring of Antibiotic Residue in Chicken Eggs in Tabriz city by FPT. International Journal of Advanced Biological and Biomedical Research, 2: 132-140.

19. Hind EA, Osman KM, Ishraga GI, Sabiel YA (2018). Detection of Oxytetracycline Residues in Table Eggs in Khartoum State, Sudan. European Journal of Nutrition \& Food Safety, 8: 148-154.

20. Idowu F, Junaid K, Paul A, Gabriel O, Paul A, Sati N, Maryam M (2010). Antimicrobial Screening of Commercial Eggs and Determination of Tetracycline Residue Using Two Microbiological Methods. International Journal of Poultry Science, 9: 959-962.

21. Islam A, Saifuddin AKM, Al Faruq A, Islam S, Shano S, Alam M, Hassan MM (2016). Antimicrobial residues in 
tissues and eggs of laying hens at Chittagong, Bangladesh. International Journal of One Health, 2: 75-80.

22. Kan CA, Petz M (2000). Residues of Veterinary Drugs in Eggs and Their Distribution between Yolk and White. Journal of Agricultural and Food Chemistry, 48: 63976403.

23. Cornejo J, Pokrant E, Figueroa F, Riquelme R, Galdames P, Di Pillo F, Jimenez-Bluhm P, Hamilton-West C (2020). Assessing Antibiotic Residues in Poultry Eggs from Backyard Production Systems in Chile, First Approach to a Non-Addressed Issue in Farm Animals. Animals, 10, 1056; doi:10.3390/ani10061056.

24. Kehinde OG, Junaidu K, Mohammed M, Abdul Rahman AM (2012). Detection of antimicrobial drug residues in commercial eggs using Premi®Test. International Journal of Poultry Science, 11: 50-54.

25. Ketta M, Tůmová E (2016). Eggshell structure, measurements, and quality-affecting factors in laying hens: a review. Czech Journal of Animal Science, 61: 299309.

26. Kolanović SB, Bilandžić N, Kos B, Šušković J, Cvetnić L, Varenina I, Luburić B (2019). Distribution and elimination of levamisole in eggs and tissues after oral administration to laying hens, determined by LC-MS/MS. Food Additives and Contaminants: Part A, 36: 729-739.

27. Krišová M, Kožárová I (2018). Detection of Residues of Antimicrobial Compounds in Eggs by the Rapid Screening Methods. Folia Veterinaria, 62: 48-55.

28. Layman DK, Rodriguez NR (2009). Egg Protein as a Source of Power, Strength, and Energy. Nutrition Today, 44: 4348.

29. Maharjan B, Neupane R, Bhatta D (2020). Antibiotic Residue in Marketed Broiler Meat of Kathmandu Metropolitan City. Archives of Veterinary Science and Medicine, 3: 1-10.

30. Moscoso S, De Los Santos FS, Andino A G, Diaz-Sanchez S, Hanning I (2015). Detection of quinolones in commercial eggs obtained from farms in the Espaíllat Province in the
Dominican Republic. Journal of Food Protection, 78: 214217.

31. Naeem M, Khan K, Rafiq S (2006). Determination of residues of Quinolones in poultry products by high pressure liquid chromatography. Journal of Applied Sciences, 6: 373-379.

32. Olatoye 0, Kayode ST (2012). Oxytetracycline residues in retail chicken eggs in Ibadan, Nigeria. Food Additives and Contaminants: Part B, 5: 255-259.

33. Polveiro RC, Vidigal PMP, Mendes TAO, Yamatogi RS, Lima MC, Moreira MAS (2020). Effects of enrofloxacin treatment on the bacterial microbiota of milk from goats with persistent mastitis. Scientific Reports, 10: 4421.

34. Rana MS, Lee SY, Kang HJ, Hur SJ (2019). Reducing veterinary drug residues in animal products: A review. Food Science of Animal Resources, 39: 687-703.

35. Réhault-Godbert S, Guyot N, Nys Y (2019). The Golden Egg: Nutritional Value, Bioactivities, and Emerging Benefits for Human Health. Nutrients, 11: 684.

36. Sachi S, Ferdous J, Sikder MH, Hussani ASM (2019). Antibiotic residues in milk: Past, present, and future. Journal of Advanced Veterinary and Animal Research, 6: 315-332.

37. Shehata AA, Ali H, Ghazali NH (2014). Detection of Aflatoxin and antibacterial residues in different types of table eggs with studying of the effect of heat treatment. Benha Veterinary Medical Journal, 27: 177-187.

38. Sirdar MM (2011). Antibiotic residues in commercial layer hens in Khartoum state, Sudan, 2007-2008. PhD Thesis, University of Pretoria, Sudan.

39. Stella O, Ezenduka EV, Anaelom NJ (2020). Screening for tylosin and other antimicrobial residues in fresh and fermented (nono) cow milk in Delta state, South-South, Nigeria. Veterinary World, 13: 458-464.

40. Yang SC, Yu MC, Lee YH, Wang JL (2016). Antibiotic Residues in Meat and Eggs in Taiwan: A Local Surveillance. British Journal of Medicine and Medical Research, 12: 1-6. 